\title{
Sex differences in
}

\section{cardiovascular drug-induced adverse reactions causing hospital admissions}

\section{Correspondence}

Professor Bruno H. Stricker PhD,

Department of Epidemiology, Erasmus

Medical Center, PO Box 2040, 3000 CA

Rotterdam, The Netherlands.

Tel.: +31 107043482

Fax: +31 107044657

E-mail: b.stricker@erasmusmc.nl

\section{Keywords}

adverse drug reaction, cardiovascular drug, hospitalization, sex difference

\section{Received}

23 August 2011

Accepted

13 April 2012

Accepted Article

Published Online

26 April 2012

\section{WHAT IS ALREADY KNOWN ABOUT} THIS SUBJECT

- Cardiovascular disease, disease outcome, drug treatment and drug response differ between men and women.

\section{WHAT THIS STUDY ADDS}

- Adverse drug reactions attributed to cardiovascular drugs that require hospital admission show differences between men and women, even after taking into account age and the total number of drug prescriptions.

\section{AIMS}

Cardiovascular disease in women is often underestimated. The effects of cardiovascular drugs differ between the sexes because of pharmacokinetic and pharmacodynamic differences. Adverse drug reactions (ADRs) within these drug classes may have serious consequences, leading to hospital admission. We aimed to study differences between men and women in hospital admissions for ADRs due to cardiovascular drugs.

\section{METHODS}

We conducted a nationwide study of all hospital admissions between 2000 and 2005 with data from the Dutch National Medical Register. Relative risks were calculated of hospital admissions due to ADRs to the different cardiovascular drug groups for women compared with men. By an ecological design, risks were adjusted for the total number of Dutch inhabitants and the total number of prescriptions.

\section{RESULTS}

In total, 14207 of the hospital admissions (34\% of all ADR-related admissions) were attributed to cardiovascular drugs [7690 in women (54\%; 95\% confidence interval 53-55\%)]. 'Anticoagulants and salicylates' $(n=8988)$,'high- and low-ceiling diuretics' $(n=2242)$ and 'cardiotonic glycosides' $(n=932)$ were responsible for the majority of the ADR-related hospital admissions. The most pronounced sex differences were seen in users of low-ceiling diuretics (relative risk 4.02; 95\% confidence interval 3.12-5.19), cardiotonic glycosides (relative risk 2.38; $95 \%$ confidence interval 2.06-2.74), high-ceiling diuretics (relative risk $2.10 ; 95 \%$ confidence interval $1.91-2.32$ ) and coronary vasodilators (relative risk $0.77 ; 95 \%$ confidence interval 0.65-0.91).

\section{CONCLUSIONS}

Clear sex differences exist in ADRs requiring hospital admission for different cardiovascular drug groups. Sex differences should be taken into account in the prescription and evaluation of drugs. 


\section{Introduction}

Cardiovascular disease is one of the most frequent causes of death in both men and women [1,2]. Presentation of disease and disease outcome differ between the sexes [3, 4]. Differences in physiology and in regulation of cardiovascular function exist between men and women. Heart size is less, heart rate is higher and the QT interval corrected for heart rate is longer in women than in men [5-8].

Development of cardiovascular disease involves different biological pathways and the effects of cardiovascular risk factors differ between men and women [9-11]. For example, low values of high-density lipoproteins contribute more to the risk profile in men, whereas risk in women is more dependent on low-density lipoproteins and triglycerides [12]. The cardiovascular risk profile is also partly determined by sex steroids; androgens and estrogens influence insulin sensitivity, atherosclerosis formation, blood pressure regulation and lipid levels [12-16].

Pharmacotherapy following myocardial infarction and the use of antihypertensives differs between men and women [17-19]. For example, women are less likely to be treated with Glycoprotein Ilb/Illa inhibitors after myocardial infarction, and hypertensive women are more likely to use a diuretic than a $\beta$-blocker, angiotensin-converting enzyme inhibitor or calcium antagonist $[17,18]$. Regarding drug response, plasma levels of metoprolol and statins reach higher levels in women $[20,21]$. Furthermore, verapamil shows higher bioavailability in women [22], and the response to angiotensin-converting enzyme inhibitors differs between the sexes [23]. However, there are no sexbased treatment guidelines for cardiovascular diseases [24-26]. In 2001, a report was brought about by the Institute of Medicine, which induced debate on the importance of sex in health research [27]. Regulatory guidelines have been changed to enhance inclusion of women in clinical trials $[28,29]$.

Differences in both presentation of disease and drug response between the sexes might require different treatment strategies to optimize efficacy and to prevent adverse drug reactions (ADRs).

We conducted a nationwide study to investigate the differences between men and women in ADRs associated with cardiovascular drugs requiring hospital admission. In this study, we also took into account the numbers of drug prescriptions. The aim of our study was to gain insight into the major differences in risk for hospital admissions for men and women and to determine the major cardiovascular drug groups causing these differences.

\section{Methods}

\section{Data sources}

Data on hospital admissions were obtained from a Dutch nationwide registry of hospital discharges. From 1 January
1986, all hospitals in The Netherlands were linked to the registry. This registry contains patient characteristics, dates of admission and discharge, main diagnoses at discharge (coded), secondary diagnoses (coded), medical specialisms (coded) and special codes indicating drug-related hospitalizations (E-codes), based on the ICD-9-CM coding system [30]. For every admission, one discharge/main diagnosis (mandatory) and up to nine secondary diagnoses (optional) are registered.

Discharge diagnoses are made by medical specialists and coded by professional code clerks on the basis of hospital discharge letters. Subsequently, the data are coded by employees of the medical registration department and registered in the local computer system before transmission to the database. Coding is performed independently of reimbursement and is independent of hospital or specialist. All diagnoses are submitted in the same format, mostly electronically. All registered admissions in the period between 2000 and 2005 were included $(n=9287162)$.

Information on prescriptions of cardiovascular drugs was obtained from the database of the Dutch Foundation of Pharmaceutical Statistics (SFK). Information on drug prescriptions is collected from 1805 pharmacies in The Netherlands (of the 1960 pharmacies in total). Data from this database were selected on pharmacological subgroup level according to the Anatomical Therapeutic Chemical (ATC) classification system. The information from these two data sources was not linked individually, but combined with an ecological design.

\section{Adverse drug reactions}

An ADR-related hospitalization was defined as a hospitalization with an E-code as secondary diagnosis, indicating an ADR as the main reason for hospitalization (E-codes are auxiliary to the discharge diagnosis). The E-codes indicate the drug group involved in the ADR. Cardiovascular drugs were covered by the E-codes 9420-9429 ('agents primarily affecting the cardiovascular system'), 9342 and 9353 ('anticoagulants and salicylates') and 9440-9445 ('water, mineral, and uric acid metabolism drugs'). These drug groups included systemic agents acting on the water balance. Adverse drug reactions occurring during hospital admission were excluded from the analysis.

\section{Data analysis}

Adverse drug reaction-related admissions associated with cardiovascular drugs were selected from all hospital admissions within the total study period. Per drug group, the number of admissions was studied per sex.

Subsequently, relative risks for hospital admission due to the specific cardiovascular drug groups were calculated for women compared with men. To make a more valid comparison, these calculations were performed only for the groups with more than 50 hospital admissions. The risks were calculated with respect to the mean number of inhabitants of The Netherlands, with respect to total 
number of admissions adjusted for age, and with respect to total number of prescriptions within the specific drug group. In the first and third analysis, as mentioned above, relative risks were calculated using Microsoft Office Excel 2003, according to the following calculation: (number of ADR-related admissions in women/mean number of female inhabitants or total number of drug prescriptions)/ (number of ADR-related admissions in men/mean number of male inhabitants or total number of drug prescriptions). Information on drug prescriptions (ATC code) was combined with the information about the drug groups (ICD-9 code), with a level of detail as much as possible.

For the age-adjusted analyses, logistic regression analyses were used, within the total number of admissions. Given the size of the study population and the rareness of the 'disease', the odds ratios (ORs) retrieved from this analysis will approximate the relative risks (RRs) [31]. Stratification by age (age $<50$ years and age $\geq 50$ years) was performed to study the potential influence of menopause.

Third, we selected the cardiovascular drug groups causing significant sex differences in the number of ADR-related hospital admissions. For these groups, the most frequent reactions were studied per sex. Adverse drug reactions accounting for at least $2.5 \%$ of the admissions within each particular drug group are demonstrated in the tables.

\section{Results}

Over the 6 year period covered in the analysis, 41260 hospital admissions were related to ADRs (17 561 in men and 23699 in women), of which 14207 admissions were associated with cardiovascular drugs (accounting for $34 \%$ of all admissions due to an ADR). Of these admissions, 7690 admissions occurred in women [54\%; 95\% confidence interval (Cl) 53-55\%]. The cardiovascular drugs mainly responsible for hospital admissions were 'anticoagulants and salicylates', accounting for more than half of all cardiovascular drug-related admissions (63\%). High-ceiling diuretics were in second place, and they were responsible for almost half of the remainder of the admissions together with the low-ceiling diuretics (16\% of the total). Cardiotonic glycosides and antihypertensive agents accounted for 7 and $5 \%$ of all cardiovascular drug-related admissions, respectively. Table 1 represents all ADR-related admissions attributed to these cardiovascular drug groups.

Clear sex differences in ADR-related hospital admissions were seen after calculating relative risks (Table 2 ). With respect to the total number of hospital admissions, women were more frequently admitted with an ADR related to high-ceiling diuretics, low-ceiling diuretics and cardiotonic glycosides than men. The relative risk for hospital admissions due to low-ceiling diuretics was highest (RR 4.02; 95\% Cl 3.12-5.19). In the age-adjusted analysis and in the analysis taking into account the total number of

\section{Table 1}

Number of hospital admissions attributed to cardiovascular drugs

\begin{tabular}{|c|c|c|c|c|}
\hline \multirow[b]{2}{*}{ Code* } & \multirow[b]{2}{*}{ Drug group } & \multicolumn{3}{|c|}{ Number of hospital admissions } \\
\hline & & Total & Women (\%) & Men (\%) \\
\hline $9342 / 53$ & Anticoagulants and salicylates & 8988 & $4392(49)$ & $4596(51)$ \\
\hline 9444 & High-ceiling diuretics & 1864 & $1272(68)$ & $592(32)$ \\
\hline 9421 & Cardiotonic glycosides & 932 & $660(71)$ & $272(29)$ \\
\hline 9426 & Antihypertensive agents (other) & 716 & $396(55)$ & $320(45)$ \\
\hline 9424 & Coronary vasodilators & 572 & $252(44)$ & $320(56)$ \\
\hline 9443 & Low-ceiling diuretics & 378 & $304(80)$ & $74(20)$ \\
\hline 9420 & Cardiac rhythm regulators & 324 & $173(53)$ & $151(47)$ \\
\hline 9429 & $\begin{array}{l}\text { Other and unspecified agents } \\
\text { primarily affecting the } \\
\text { cardiovascular system }\end{array}$ & 178 & $100(56)$ & $78(44)$ \\
\hline 9422 & $\begin{array}{l}\text { Antilipaemic and } \\
\text { antiarteriosclerotic drugs }\end{array}$ & 74 & $40(54)$ & $33(46)$ \\
\hline 9441 & Purine derivative diuretics & 47 & $24(51)$ & $23(49)$ \\
\hline 9425 & Vasodilators (other) & 43 & $19(44)$ & $24(56)$ \\
\hline 9445 & $\begin{array}{l}\text { Electrolytic, caloric and } \\
\text { water-balance agents }\end{array}$ & 43 & $28(65)$ & $15(35)$ \\
\hline 9442 & $\begin{array}{l}\text { Carbonic acid anhydrase } \\
\text { inhibitors }\end{array}$ & 32 & $20(63)$ & $12(37)$ \\
\hline & Othert & 16 & $10(62)$ & $6(38)$ \\
\hline
\end{tabular}

*Code according to the ICD-9 classification. TOther drugs include the following: antivaricose drugs, including sclerosing agents (9427); capillary-active drugs (9428); mineral salts, not elsewhere classified (other; 9446); ganglion-blocking agents (9423); and mercurial diuretics (9440)

prescriptions within this drug group, the increased risk in women remained ( $\mathrm{RR} 2.14 ; 95 \% \mathrm{Cl}$ 1.66-2.75). Risks for admission related to high-ceiling diuretics were also higher in women, remaining after adjustment for the number of prescriptions (RR 1.13; 95\% Cl 1.02-1.24).

Cardiotonic glycosides accounted for a risk for women to be hospitalized with an ADR which was twice as high as for men (RR 2.38; 95\% Cl 2.06-2.74). Adjustment for number of prescriptions still showed a $63 \%$ higher risk in women for an ADR-related hospital admission.

Adverse drug reaction-related admissions associated with coronary vasodilators were more frequent in men. The age-adjusted relative risk with respect to the total number of admissions was 0.66 (95\% Cl 0.56-0.78). After taking into account the total number of prescriptions, the relative risk changed only slightly (RR $0.71 ; 95 \% \mathrm{Cl} 0.60-0.84$ ). Hospital admissions with an ADR due to 'anticoagulants and salicylates' were also more frequent in men (RR $0.94 ; 95 \% \mathrm{Cl}$ 0.90-0.98). After taking into account the total number of drug prescriptions, the risk estimate changed (RR 1.04; $95 \%$ Cl 1.00-1.08); no significant sex difference remained. Stratification by age (age $<50$ years and age $\geq 50$ years) showed only few admissions below 50 years of age for all drug groups. Consequently, in the age group $\geq 50$ years, relative risks were similar to the total group, and menopausal differences could not be studied adequately (data not shown).

For the drug groups with significant sex differences, the types of adverse reactions that were reported as cause of 


\section{Table 2}

Relative risks for women for an adverse drug reaction-related hospital admission attributed to a cardiovascular drug (anatomical therapeutic chemical code)

\begin{tabular}{|c|c|c|c|c|}
\hline Code* & Drug group & $\mathrm{RR}+(95 \% \mathrm{Cl}) \neq$ & $\mathrm{RR}+(95 \% \mathrm{Cl}) \S$ & $\mathrm{RR+}(95 \% \mathrm{Cl}) \mathrm{n}$ \\
\hline 9444 & High-ceiling diuretics (C03C) & $2.10(1.91-2.32)$ & $1.73(1.57-1.91)$ & $1.13(1.02-1.24)$ \\
\hline 9426 & Antihypertensive agents (other) $(\mathrm{CO} 2 \mathrm{~A}+\mathrm{C})$ & $1.21(1.05-1.40)$ & $1.08(0.93-1.25)$ & $0.87(0.75-1.01)$ \\
\hline 9424 & Coronary vasodilators (C01D) & $0.77(0.65-0.91)$ & $0.66(0.56-0.78)$ & $0.71(0.60-0.84)$ \\
\hline 9443 & Low-ceiling diuretics (C03A) & $4.02(3.12-5.19)$ & $3.44(2.66-4.43)$ & $2.14(1.66-2.75)$ \\
\hline 9420 & Cardiac rhythm regulators $(\mathrm{CO1B}+\mathrm{C07A})$ & $1.12(0.90-1.20)$ & $0.98(0.78-1.21)$ & $0.89(0.71-1.10)$ \\
\hline
\end{tabular}

Abbreviations: $\mathrm{Cl}$, confidence interval; and RR, relative risk. ${ }^{*}$ Code according to the ICD-9 classification. †Relative risks show the risk for women to be hospitalized, with men as the reference. ¥Relative risk with number of Dutch inhabitants used as denominator. §Relative risk within total hospital admissions, adjusted for age. $₫$ Relative risk with total prescriptions used as denominator.

\section{Table 3}

Most frequently occurring reactions per cardiovascular drug group

\begin{tabular}{|c|c|c|c|}
\hline Drug group & $\begin{array}{l}\text { Women } \\
n(\%)^{*}\end{array}$ & $\begin{array}{l}\text { Men } \\
n(\%) *\end{array}$ & $\mathrm{RR}+(95 \% \mathrm{Cl})$ \\
\hline \multicolumn{4}{|l|}{ High-ceiling diuretics } \\
\hline Volume depletion & $340(26.7)$ & $225(38.0)$ & $0.79(0.67-0.94)$ \\
\hline Hyposmolality/hyponatraemia & $451(35.5)$ & $78(13.2)$ & $3.04(2.39-3.86)$ \\
\hline Hypopotassaemia & $106(8.3)$ & $27(4.6)$ & $2.06(1.35-3.15)$ \\
\hline Kidney/ureter disorder, unspecified & $57(4.5)$ & $48(8.1)$ & $0.62(0.42-0.92)$ \\
\hline Hyperpotassaemia & $33(2.6)$ & $42(7.1)$ & $0.41(0.26-0.65)$ \\
\hline Renal failure & $52(4.1)$ & $29(4.9)$ & $0.94(0.60-1.48)$ \\
\hline \multicolumn{4}{|l|}{ Low-ceiling diuretics } \\
\hline Hyposmolality/hyponatraemia & $191(62.8)$ & $23(31.1)$ & $4.32(2.80-6.66)$ \\
\hline Hypopotassaemia & $57(18.8)$ & $13(17.6)$ & $2.28(1.25-4.17)$ \\
\hline Volume depletion & $8(2.6)$ & $6(8.1)$ & $0.69(0.24-2.00)$ \\
\hline Poisoning & $8(2.6)$ & $2(2.7)$ & $2.08(0.44-9.80)$ \\
\hline \multicolumn{4}{|l|}{ Cardiotonic glycosides } \\
\hline Poisoning & $291(44.1)$ & $101(37.1)$ & $1.93(1.54-2.43)$ \\
\hline Unspecified adverse effect & $190(28.8)$ & $77(28.3)$ & $1.66(1.27-2.16)$ \\
\hline Cardiac dysrhythmias & $48(7.3)$ & $31(11.4)$ & $1.04(0.66-1.63)$ \\
\hline \multicolumn{4}{|l|}{ Coronary vasodilators } \\
\hline Syncope/collapse & $128(50.8)$ & $170(53.1)$ & $0.68(0.54-0.86)$ \\
\hline Cardiac dysrhythmias & $22(8.7)$ & $18(5.6)$ & $1.10(0.59-2.06)$ \\
\hline Poisoning & $10(4.0)$ & $10(3.1)$ & $0.90(0.38-2.17)$ \\
\hline Thyrotoxicosis & $7(2.8)$ & $10(3.1)$ & $0.63(0.24-1.66)$ \\
\hline
\end{tabular}

*The percentages show the number of specific reactions in relation to the total number of ADR-related hospital admissions within the sexes. $t$ Relative risks (RRs) show the risk for women to be hospitalized with the particular ADR, with men as the reference. Relative risks are calculated with the total number of prescriptions per sex as a denominator. Adverse reactions of 'antihypertensive agents (other)' were not analysed further in this table, becasuse it had no additional value.

admission are shown in Table 3. The most frequent reaction in women due to high-ceiling diuretics was hyposmolality/hyponatraemia (36\%), followed by volume depletion (27\%). In men, volume depletion accounted for $38 \%$ of the ADR-related admissions in this drug group. Hyposmolality/hyponatraemia was also the most frequent reason for admission for the low-ceiling diuretics. However, in women this proportion was remarkably higher $(63 \%$, compared with $31 \%$ in men). A low blood level of potassium was the second-most frequent ADR in this group, accounting for 19 and $18 \%$ of ADR-related admissions in women and men, respectively. A remarkable difference was seen in the risk for the various types of reactions due to high-ceiling diuretics and low-ceiling diuretics; women suffered more frequently from electrolyte disorders, whereas men suffered more from volume depletion.

Within the cardiotonic glycosides, poisoning, unspecified adverse effects and cardiac dysrhythmias accounted for the highest frequency of ADR-related admissions in both men and women. Of the admissions related to coronary vasodilators, more than half were due to syncope/ collapse (51\% in women vs. 53\% in men). 


\section{Discussion}

Cardiovascular drugs were responsible for a large part of adverse drug reactions requiring hospital admission, as described previously in the literature [32-34]. In addition, these drugs were the main ones responsible for potentially preventable medication-related hospital admissions and were involved in all five major reasons for preventable admissions [35]. In our study, generally speaking women were more frequently admitted to hospital with an ADR related to cardiovascular drugs than men, but the risks differed according to the drug group. Previous studies have already shown different effects within the sexes for different cardiovascular drugs [36-38].

Our results show that within the class of cardiovascular drugs, 'anticoagulants and salicylates' accounted for over half of all ADR-related hospital admissions, mainly haemorrhages. Other studies also showed a relatively high contribution of these drugs [32-34]. One should be careful about interpreting results based on indication, because analgesic use of salicylates could not be distinguished from use as a platelet inhibitor. However, prescribed salicylates are mainly indicated for platelet inhibition, so analgesic use probably concerns a low percentage of use of the total number of prescriptions.

Of the other hospital admissions related to cardiovascular drugs, low-ceiling diuretics and high-ceiling diuretics together accounted for almost half (and $16 \%$ of the total) of these admissions. Diuretics were responsible for the major difference between the sexes in risk for an ADRrelated admission. Adverse drug reactions due to these drugs are predominantly type A reactions, which are mainly augmented pharmacological effects, and are well documented $[39,40]$. The reason, however, why women would suffer more frequently from a specific ADR, is less clear. It is often thought that diuretics are more frequently prescribed in women [18]. A reason for this might be that increased blood pressure in postmenopausal women is partly due to an increase in salt sensitivity [41]. Therefore, diuretics are thought to be most effective in the treatment of hypertension. Our study shows that even after adjustment for drug use, this sex difference remains.

In a rat model, a lower clearance of high-ceiling diuretics was shown in females, with an increased diuretic, natriuretic and kaliuretic response $[42,43]$. In other animal studies, differences were seen between males and females in expression of the kidney transporters organic anion transporter and the thiazide-sensitive $\mathrm{NaCl}$ cotransporter (NCC), which play a role in this mechanism $[44,45]$. Regulation and expression of these transporters is influenced by the steroid hormones testosterone and estrogen [46-48]. It is therefore very likely that hormonal differences also result in different treatment effects of diuretics. In our study, differences were also seen in the types of adverse reactions; volume depletion was more pronounced in men, whereas women suffered more from electrolyte dis- orders. This supports the idea that diuretic-related ADRs in general are more water related than salt related and have different consequences in men and women.

Cardiotonic glycosides and coronary vasodilators, which also contribute significantly to the total number of ADR-related admissions, are two of the other drug groups showing sex differences in risk for admission. Cardiotonic glycosides are responsible for a twofold higher risk in women than men for hospital admission with an ADR. In a previous trial in heart failure patients, digoxin treatment resulted in a higher mortality in women, but not in men [49]. Digoxin, which is probably the most well-known and most frequently used drug within this drug group, is transported by P-glycoprotein. Genetic variation within the gene encoding for this transporter (MDR1) was shown to affect the kinetics of digoxin, resulting in a change in digoxin levels [50]. As expression of this drug-efflux transporter is highest in men, drug transport is faster in men than in women [51]. In women, this leads to a reduction in drug elimination and prolonged half-life. Sex steroids modify P-glycoprotein activity, with an inhibitory effect of progestins [52]. This also suggests differences between pre- and postmenopausal women. Unfortunately, we were not able to study this with our data.

Coronary vasodilators were also responsible for a large number of hospital admissions. The risk for admissions related to this drug group was higher in men. The most commonly used drugs within this drug group are the nitrates, with nitroglycerine (glyceryl trinitrate) probably being the most well-known example. The metabolism of glyceryl trinitrate is complex. Two major mechanisms have been distinguished in the biotransformation of the drug. One of the mechanisms leads to direct nitric oxide production; the second mechanism leads to production of inorganic nitrite ions $\left(\mathrm{NO}_{2}^{-}\right)$, both directly affecting vasodilation and blood flow [53]. For these two major mechanisms, at least five metabolizing pathways have been hypothesized: two non-enzymatic and three enzymatic pathways $[54,55]$. Owing to the complex metabolism of these coronary vasodilators, it is hard to explain the sex difference found in this study. Possible explanations are the difference in vessel size and differences in the endothelial mechanisms involved in vasodilaattion $[56,57]$. It is unknown whether sex influences vascular tolerance, which is a known phenomenon of these drugs.

One of the strengths of our study is the availability of nationwide data on discharge diagnoses of all hospital admissions over a 6 year period. Data on drug use were also available for the same 6 year period, and served as a denominator. Owing to the ecological design of the study, it was not possible to match the data on drug use (which were not discernable on an individual basis) with the ADR-related hospital admissions. Therefore, interaction between the various drugs could not be studied. Another limitation is that the data within the drug categories did not match completely. This is due to the different coding 
systems used by the two databases in our study. Another issue is that it might have transpired that an ADR presented itself during admission and was not the direct reason for admission. However, in our opinion, the frequency with which ADRs occurring during hospitalization are coded as main diagnosis is very probably low. Moreover, as this misclassification would be nondifferential, it is not likely to bias our comparison between men and women. Owing to the passive coding of ADR relatedness of the admission diagnosis at discharge, the cumulative incidence of ADR-related admissions is probably substantially underestimated. In general, we expect that underrecognition of serious ADRs (i.e. requiring hospital admission) will be nondifferential, because symptoms are serious and will lead to admission anyhow.

In conclusion, clear sex differences exist in ADRs requiring hospital admission for some of the cardiovascular drug groups. In addition to the pharmacokinetic and pharmacodynamic factors of the specific drugs, the number and types of concomitantly used drugs are important in identifying high-risk patients. Furthermore, comorbidity, such as depression, and severity of the underlying disease are of importance in the determination of ADRs. Depression is associated with a higher risk of drug intolerance and adverse reactions $[58,59]$. As perception of symptoms may differ between men and women, due to sympathetic and parasympathetic differences, one should be aware of differences in presentation of diseases and ADRs [60]. More research is needed to study the possible causative mechanisms and contributory factors for the specific drugs, and whether interactions play a role. Furthermore, this study underlines the necessity of studying (adverse) effects of drug therapy in both sexes. Prescription adjustments for high-risk drugs should be considered to prevent serious ADRs requiring hospital admission.

\section{Competing Interests}

There are no competing interests to declare.

The authors gratefully acknowledge support from the Ministry of Health, Welfare and Sport in preparing this manuscript, with special thanks to Ms M. Schreurs.

\section{REFERENCES}

1 Ford ES, Capewell S. Coronary heart disease mortality among young adults in the U.S. from 1980 through 2002: concealed leveling of mortality rates. J Am Coll Cardiol 2007; 50: 2128-32.

2 O'Flaherty M, Ford E, Allender S, Scarborough P, Capewell S. Coronary heart disease trends in England and Wales from 1984 to 2004: concealed levelling of mortality rates among young adults. Heart 2008; 94: 178-81.
3 Goldberg R, Goff D, Cooper L, Luepker R, Zapka J, Bittner V, Osganian S, Lessard D, Cornell C, Meshack A, Mann C, Gilliland J, Feldman H. Age and sex differences in presentation of symptoms among patients with acute coronary disease: the REACT Trial. Rapid Early Action for Coronary Treatment. Coron Artery Dis 2000; 11:399-407.

4 Berger JS, Elliott L, Gallup D, Roe M, Granger CB, Armstrong PW, Simes RJ, White HD, Van de Werf F, Topol EJ, Hochman JS, Newby LK, Harrington RA, Califf RM, Becker RC, Douglas PS. Sex differences in mortality following acute coronary syndromes. JAMA 2009; 302: 874-82.

5 Levy D, Savage DD, Garrison RJ, Anderson KM, Kannel WB, Castelli WP. Echocardiographic criteria for left ventricular hypertrophy: the Framingham Heart Study. Am J Cardiol 1987; 59: 956-60.

6 de Simone G, Devereux RB, Roman MJ, Ganau A, Chien S, Alderman $\mathrm{MH}$, Atlas S, Laragh JH. Gender differences in left ventricular anatomy, blood viscosity and volume regulatory hormones in normal adults. Am J Cardiol 1991; 68: 1704-8.

7 Umetani K, Singer DH, McCraty R, Atkinson M. Twenty-four hour time domain heart rate variability and heart rate: relations to age and gender over nine decades. J Am Coll Cardiol 1998; 31:593-601.

8 Liu XK, Katchman A, Drici MD, Ebert SN, Ducic I, Morad M, Woosley RL. Gender difference in the cycle length-dependent QT and potassium currents in rabbits. J Pharmacol Exp Ther 1998; 285: 672-9.

9 Tan YY, Gast GC, van der Schouw YT. Gender differences in risk factors for coronary heart disease. Maturitas 2010; 65: 149-60.

10 Barrett-Connor E, Bush TL. Estrogen and coronary heart disease in women. JAMA 1991; 265: 1861-7.

11 Liu PY, Death AK, Handelsman DJ. Androgens and cardiovascular disease. Endocr Rev 2003; 24: 313-40.

12 Vitale C, Mendelsohn ME, Rosano GM. Gender differences in the cardiovascular effect of sex hormones. Nat Rev Cardiol 2009; 6: 532-42.

13 Reckelhoff JF. Gender differences in the regulation of blood pressure. Hypertension 2001; 37: 1199-208.

14 Reckelhoff JF. Sex steroids, cardiovascular disease, and hypertension: unanswered questions and some speculations. Hypertension 2005; 45: 170-4.

15 Mendelsohn ME, Karas RH. Molecular and cellular basis of cardiovascular gender differences. Science 2005; 308 : 1583-7.

16 Malkin CJ, Pugh PJ, Jones RD, Jones TH, Channer KS. Testosterone as a protective factor against atherosclerosis-immunomodulation and influence upon plaque development and stability. J Endocrinol 2003; 178: 373-80.

17 Tavris D, Shoaibi A, Chen AY, Uchida T, Roe MT, Chen J. Gender differences in the treatment of non-ST-segment elevation myocardial infarction. Clin Cardiol 2010; 33: 99-103. 
18 Klungel OH, de Boer A, Paes AH, Seidell JC, Bakker A. Sex differences in antihypertensive drug use: determinants of the choice of medication for hypertension. J Hypertens 1998; 16: 1545-53.

19 Thoenes M, Neuberger HR, Volpe M, Khan BV, Kirch W, Bohm M. Antihypertensive drug therapy and blood pressure control in men and women: an international perspective. J Hum Hypertens 2010; 24: 336-44.

20 Luzier AB, Killian A, Wilton JH, Wilson MF, Forrest A, Kazierad DJ. Gender-related effects on metoprolol pharmacokinetics and pharmacodynamics in healthy volunteers. Clin Pharmacol Ther 1999; 66: 594-601.

21 Sacks FM, Pfeffer MA, Moye LA, Rouleau JL, Rutherford JD, Cole TG, Brown L, Warnica JW, Arnold JM, Wun CC, Davis BR, Braunwald $\mathrm{E}$. The effect of pravastatin on coronary events after myocardial infarction in patients with average cholesterol levels. Cholesterol and Recurrent Events Trial investigators. N Engl J Med 1996; 335: 1001-9.

22 Krecic-Shepard ME, Barnas CR, Slimko J, Schwartz JB. Faster clearance of sustained release verapamil in men versus women: continuing observations on sex-specific differences after oral administration of verapamil. Clin Pharmacol Ther 2000; 68: 286-92.

23 Cherney DZ, Sochett EB, Miller JA. Gender differences in renal responses to hyperglycemia and angiotensin-converting enzyme inhibition in diabetes. Kidney Int 2005; 68: 1722-8.

24 Chobanian AV, Bakris GL, Black HR, Cushman WC, Green LA, Izzo JL Jr, Jones DW, Materson BJ, Oparil S, Wright JT Jr, Roccella EJ, National Heart L, Blood Institute Joint National Committee on Prevention DE, Treatment of High Blood P, National High Blood Pressure Education Program Coordinating C. The Seventh Report of the Joint National Committee on Prevention, Detection, Evaluation, and Treatment of High Blood Pressure: the JNC 7 report. JAMA 2003; 289: 2560-72.

25 Antman EM, Anbe DT, Armstrong PW, Bates ER, Green LA, Hand M, Hochman JS, Krumholz HM, Kushner FG, Lamas GA, Mullany CJ, Ornato JP, Pearle DL, Sloan MA, Smith SC Jr, Alpert JS, Anderson JL, Faxon DP, Fuster V, Gibbons RJ, Gregoratos G, Halperin JL, Hiratzka LF, Hunt SA, Jacobs AK, American College of Cardiology/American Heart Association Task Force on Practice G. ACC/AHA guidelines for the management of patients with ST-elevation myocardial infarction-executive summary: a report of the American College of Cardiology/American Heart Association Task Force on Practice Guidelines (Writing Committee to Revise the 1999 Guidelines for the Management of Patients With Acute Myocardial Infarction). Circulation 2004; 110: 588-636.

26 Orn S, Dickstein K. Pharmacotherapy following myocardial infarction-a review of current treatment practices. Expert Opin Pharmacother 2000; 1: 1105-16.

27 Committee on Understanding the Biology of Sex and Gender Differences B, Policy oHS. Exploring the Biological Contributions to Human Health: Does Sex Matter? . Washington, DC: Institute of Medicine, 2001; Contract No.: Document Number.
28 Ruiz Cantero MT, Angeles Pardo M. European Medicines Agency policies for clinical trials leave women unprotected. J Epidemiol Community Health 2006; 60: 911-3.

29 Kim AM, Tingen CM, Woodruff TK. Sex bias in trials and treatment must end. Nature 2010; 465: 688-9.

30 WHO. International classification of diseases, 9th revision, clinical modification (ICD-9), 1978. Available at http://icd9cm.chrisendres.com/ (last accessed 15 May 2012).

31 Greenland S. Interpretation and choice of effect measures in epidemiologic analyses. Am J Epidemiol 1987; 125: 761-8.

32 van der Hooft CS, Dieleman JP, Siemes C, Aarnoudse AJ, Verhamme KM, Stricker BH, Sturkenboom MC. Adverse drug reaction-related hospitalisations: a population-based cohort study. Pharmacoepidemiol Drug Saf 2008; 17: 365-71.

33 Onder G, Pedone C, Landi F, Cesari M, Della Vedova C, Bernabei R, Gambassi G. Adverse drug reactions as cause of hospital admissions: results from the Italian Group of Pharmacoepidemiology in the Elderly (GIFA). J Am Geriatr Soc 2002; 50: 1962-8.

34 Hallas J, Gram LF, Grodum E, Damsbo N, Brosen K, Haghfelt T, Harvald B, Beck-Nielsen J, Worm J, Jensen KB, Davidsen O, Frandsen NE, Hagen C, Andersen M, Frolund F, Kromann-Andersen $\mathrm{H}$, Schou J. Drug related admissions to medical wards: a population based survey. Br J Clin Pharmacol 1992; 33:61-8.

35 Leendertse AJ, Egberts AC, Stoker LJ, van den Bemt PM, Group HS. Frequency of and risk factors for preventable medication-related hospital admissions in the Netherlands. Arch Intern Med 2008; 168: 1890-6.

36 Franconi F, Brunelleschi S, Steardo L, Cuomo V. Gender differences in drug responses. Pharmacol Res 2007; 55: 81-95.

37 Jochmann N, Stangl K, Garbe E, Baumann G, Stangl V. Female-specific aspects in the pharmacotherapy of chronic cardiovascular diseases. Eur Heart J 2005; 26: 1585-95.

38 Sullivan JC. Sex and the renin-angiotensin system: inequality between the sexes in response to RAS stimulation and inhibition. Am J Physiol Regul Integr Comp Physiol 2008; 294: R1220-6.

39 Greenberg A. Diuretic complications. Am J Med Sci 2000; 319: 10-24.

40 Sarafidis PA, Georgianos PI, Lasaridis AN. Diuretics in clinical practice. Part II: electrolyte and acid-base disorders complicating diuretic therapy. Expert Opin Drug Saf 2010; 9: 259-73.

41 Pechere-Bertschi A, Burnier M. Female sex hormones, salt, and blood pressure regulation. Am J Hypertens 2004; 17: 994-1001.

42 Cerrutti JA, Quaglia NB, Brandoni A, Torres AM. Effects of gender on the pharmacokinetics of drugs secreted by the renal organic anions transport systems in the rat. Pharmacol Res 2002; 45: 107-12.

43 Brandoni A, Villar SR, Torres AM. Gender-related differences in the pharmacodynamics of furosemide in rats.

Pharmacology 2004; 70: 107-12. 
44 Cerrutti JA, Brandoni A, Quaglia NB, Torres AM. Sex differences in $\mathrm{p}$-aminohippuric acid transport in rat kidney: role of membrane fluidity and expression of OAT1. Mol Cell Biochem 2002; 233: 175-9.

45 Groves CE, Suhre WB, Cherrington NJ, Wright SH. Sex differences in the mRNA, protein, and functional expression of organic anion transporter (Oat) 1, Oat3, and organic cation transporter (Oct) 2 in rabbit renal proximal tubules. J Pharmacol Exp Ther 2006; 316: 743-52.

46 Reyes JL, Melendez E, Alegria A, Jaramillo-Juarez F. Influence of sex differences on the renal secretion of organic anions. Endocrinology 1998; 139: 1581-7.

47 Chen Z, Vaughn DA, Fanestil DD. Influence of gender on renal thiazide diuretic receptor density and response. J Am Soc Nephrol 1994; 5: 1112-9.

48 Verlander JW, Tran TM, Zhang L, Kaplan MR, Hebert SC. Estradiol enhances thiazide-sensitive $\mathrm{NaCl}$ cotransporter density in the apical plasma membrane of the distal convoluted tubule in ovariectomized rats. J Clin Invest 1998; 101: 1661-9.

49 Rathore SS, Wang Y, Krumholz HM. Sex-based differences in the effect of digoxin for the treatment of heart failure. $\mathrm{N}$ Engl J Med 2002; 347: 1403-11.

50 Aarnoudse AJ, Dieleman JP, Visser LE, Arp PP, van der Heiden IP, van Schaik RH, Molokhia M, Hofman A, Uitterlinden AG, Stricker BH. Common ATP-binding cassette $B 1$ variants are associated with increased digoxin serum concentration. Pharmacogenet Genomics 2008; 18: 299-305.

51 Schuetz EG, Furuya KN, Schuetz JD. Interindividual variation in expression of P-glycoprotein in normal human liver and secondary hepatic neoplasms. J Pharmacol Exp Ther 1995; 275: 1011-8.
52 Frohlich M, Albermann N, Sauer A, Walter-Sack I, Haefeli WE, Weiss J. In vitro and ex vivo evidence for modulation of P-glycoprotein activity by progestins. Biochem Pharmacol 2004; 68: 2409-16.

53 Dejam A, Hunter CJ, Tremonti C, Pluta RM, Hon YY, Grimes G, Partovi K, Pelletier MM, Oldfield EH, Cannon RO 3rd, Schechter AN, Gladwin MT. Nitrite infusion in humans and nonhuman primates: endocrine effects, pharmacokinetics, and tolerance formation. Circulation 2007; 116: 1821-31.

54 Hashimoto S, Kobayashi A. Clinical pharmacokinetics and pharmacodynamics of glyceryl trinitrate and its metabolites. Clin Pharmacokinet 2003; 42: 205-21.

55 Ignarro LJ. After 130 years, the molecular mechanism of action of nitroglycerin is revealed. Proc Natl Acad Sci U S A 2002; 99: 7816-7.

56 Sader MA, Celermajer DS. Endothelial function, vascular reactivity and gender differences in the cardiovascular system. Cardiovasc Res 2002; 53: 597-604.

$57 \mathrm{McCulloch} \mathrm{Al}$, Randall MD. Sex differences in the relative contributions of nitric oxide and EDHF to agonist-stimulated endothelium-dependent relaxations in the rat isolated mesenteric arterial bed. Br J Pharmacol 1998; 123: 1700-6.

58 Davies SJ, Jackson PR, Ramsay LE, Ghahramani P. Drug intolerance due to nonspecific adverse effects related to psychiatric morbidity in hypertensive patients. Arch Intern Med 2003; 163: 592-600.

59 Onder G, Penninx BW, Landi F, Atkinson H, Cesari M, Bernabei R, Pahor M. Depression and adverse drug reactions among hospitalized older adults. Arch Intern Med 2003; 163: 301-5.

60 Mackay MH, Ratner PA, Johnson JL, Humphries KH, Buller CE. Gender differences in symptoms of myocardial ischaemia. Eur Heart J 2011; 32: 3107-14. 